\title{
Comparing Math Anxiety of Scientific Facilities Students as Related to Achievement, and Some Variables
}

\author{
Mamoon M. Mubark Al-Shannaq \\ Dr., Department of Curriculum and Instruction, Faculty of Education, Yarmouk \\ University, Irbid, Jordan, mamoon.shannaq@yu.edu.jo
}

\section{Johanna Leppavirta}

Dr., Department of Electrical and Communications Engineering, Aalto University, Finland, johanna.leppavirta@outokumpu.com

This paper examines the relationship between mathematics anxiety and students' performance, gender, length of the studies and postponed calculus courses in scientific faculties. The data were collected from Calculus 2 students at the Hashemite University during the academic Year 2015/2016. The student sample consisted of 179 students with both genders. The instrument of the study was Electromagnetics Mathematics Anxiety Rating Scale (EMARS), with subscales (usefulness, confidence, fear of asking for help, persistency). The modified EMARS instrument is a five-point Likert scale which consists of (15) items. To analyze the data, the researchers found correlations, means, standard deviations, Tvalue, and ANOVA. The results show that there was negative effect between mathematics anxiety and mathematics performance, also there were no gender differences in mathematics anxiety. In relation to length of the studies, faculty, and postponement, the study found that mathematics anxiety scores were significantly higher for seniors, information technology students, and for students that had postponed their mathematics studies.

Keywords: math anxiety, scientific facilities, achievement in Calculus, gender, postponement of calculus courses

\section{INTRODUCTION}

The increasingly students' achievement in mathematics, under preparedness for higher education in related courses and career, and lack of interest in mathematics, have been an international concern for many years (Bull, 2009; Gilham\& Chu, 1995; Hodge, 2002, Hourigan \& O'Donoghue, 2007; Luk, 2005). In many domains, mathematics is considered as an important service subject that provides, students with needed skill to succeed in their studies (Metje et al., 2007). Even in cases where students by

Citation: Al-Shannaq, M. M., \& Leppayirta, J. (2020). Comparing Math Anxiety of Scientific Facilities Students as Related to Achievement, and Some Variables. International Journal of Instruction, 13(1), 341-352. https://doi.org/10.29333/iji.2020.13123a 
engineering, science and technology courses, generally may have the ability to study mathematics and hold positive attitudes towards the subject. Research has shown that many suffer anxiety in mathematics that limits their ability to engage with subject and perform mathematical tasks (Ashcraft \& Moore, 2009; Leppävirta, 2011; Onwuegbuzie\& Daley, 1999).

Mathematics anxiety is defined as a feeling of tension or fear that disrupts the manipulation of numbers and the solving of mathematical problems negative attitudes toward mathematics learning (Bessant, 1995; Richardson \& Suinn, 1972; Tobias, 1994). Also, Math anxiety defined as "feelings of fear and tension in anticipation of situations demanding the application of mathematics knowledge" (Brunyé et al., 2013, p. 1). The relationship between mathematical anxiety and achievement in mathematics is a complex one.

\section{CONTEXT AND REVIEW OF LITERATURE}

Many studies have reported the negative effects of mathematics anxiety on students' performance and achievement in mathematics (Artemenko, et al 2015; Ashcraft \& Kirk, 2001; Ma, 1999; Ma \&Xu, 2004; Woodard (2004)). The meta-analysis conducted by Ma (1999) found that the relationship between mathematics anxiety and mathematics achievement is significant and consistent across grade levels. What researchers are uncertain is whether high anxiety is a cause of low mathematics achievement, or whether high anxiety is an effect of low mathematics achievement. Ma and $\mathrm{Xu}$ (2004) found in their longitudinal analysis among middle and high school students that prior low mathematics achievement had a weak but significant relation to higher scores in mathematics anxiety in later school life. In contrast, prior high mathematics anxiety was not the cause of later low achievement in mathematics.

Prior research reveals that mathematics anxiety does not have a single cause, but is in fact, the result of many different factors such as students' competence beliefs, poor study skills, rote learning without understanding, and teachers' attitude (Guita, \& Tan, 2018; Norwood, 1994; Tariq \& Durrani, 2011). However, some studies propose that the principal cause of mathematics anxiety has been the teaching methodologies (Burns, 1998; Stuart, 2000; Greenwood, 1984). The traditional methods of teaching mathematics in certain universities do not encourage reasoning and understanding, rather emphasize heavily on standards of mathematical proof and procedural fluency. Crawford et al. (1994) studied mathematics students at universities in Australia and their study revealed that over $75 \%$ of students perceived of mathematics as a fragmented body of knowledge, and learned it using a repetitive and surface approach. The study conducted by Leppävirta (2011) among engineering students found a significant decline in procedural performance scores with increasing mathematics anxiety. The decline, however, was less evident in test scores that measured students' conceptual understanding. In fact, highly math-anxious students performed better in the concept test than did students with moderate mathematics anxiety.

The most pervasive consequence of mathematics anxiety is avoidance (Ashcraft, 2002). High math-anxious students' lesser mathematics abilities lead them to avoid 
mathematics-related tasks and consequently make them less competent in mathematics. Recent studies on cognitive processing suggest that mathematics anxiety may result from deficits in numerical processing and reduction of processing capacity in working memory that compromise the development of higher-level mathematical skills (Aschcraft, 2001; Maloney et al., 2011). In overall, mathematics anxiety has both immediate cognitive and long-term educational consequences that need to be considered when trying to reduce students' mathematics anxiety and to increase their confidence and persistency in mathematics.

In addition, many studies have examined gender differences in mathematics achievement (Dane, 2005; Peker, \&Ertekin, 2011,Wahid,Yusof,\&Nor, 2018). For example, Dane (2005) conducted gender differences and faculty programs in mathematics anxiety. The sample size was consisting of 221 males, and 142 female and 238 from education faculty and 125 sciences. The result showed no gender differences and faculty type in relation to mathematics anxiety. Moreover, the lower mathematics performance of science faculty leads to mathematics anxiety. Whereas, Wahid, Yusof \& Nor (2018) found female students were more anxious than male students.

The aim of this study is to investigate the relationship between undergraduates' mathematics anxiety and mathematics performance. The key questions this study aims to answer are: 1) What relationships, if any, exist between math anxiety and undergraduate students' performance? How are these constructs mediated by demographic characteristics, such as gender, length of studies, and postponement of math courses? 2) In what way, if any, does math anxiety vary across faculties?

\section{METHOD}

\section{Participants}

Participants were recruited from scientific faculties at the Hashemite University in Jordan in the academic Year 2015/2016. The students $(N=179)$ were enrolled in Calculus 2 course and consisted of students from three different faculties: science $(n=79)$, engineering $(n=62)$ and Prince Al-Hussein Abdallah II for information technology $(n=38)$. The Calculus 2 course was chosen for this study because it is a compulsory course for engineering, science, and information technology students. Furthermore, Calculus 2 was also chosen in order to compare students' prior math performance in Calculus 1 course with math anxiety.

Almost fifty percent of the students (179 out of 355) participating in the course completed the survey. The sample consisted of (4) classes with average (45) students in each class. The reasons for attrition were that not all students enrolled in the course were present that day when the survey was conducted or that not all students consented to be part of the study. The participant age range was from 18-22, with the approximately mean age of 20 . The sample consisted of 100 males (56\%) and 79 females (44\%). Slightly over half of the students $(53 \%)$ were sophomores, $18 \%$ were freshmen, and $14 \%$ and $15 \%$ of the students were third- and fourth-year students, respectively. Altogether $106(59 \%)$ students had postponed their calculus courses, leaving less than half of the sample $(41 \%)$ containing students that were taking the courses in due time. 
The course expected to be taken is the second semester first year, but because the first author conducted the questionnaire in the first semester, so we found the most percentage of the students was in the second year. Moreover, freshmen were (18\%), the admission of those students was in the second semester in the academic year 2014/2015 and the first semester for 2015/2016 was considered the first year for them. In addition, we found only 4 classes for the calculus 2 in the first semester, whereas there were normally more than 10 classes in the second semester.

\begin{abstract}
Measures
Electromagnetics Mathematics Anxiety Rating Scale (EMARS). The EMARS subscales (usefulness, confidence, fear of asking for help, persistency) are established measures of students' perceived math anxiety when learning electromagnetics (Lappävirta, 2007; Leppävirta 2011). The original instrument has provided reliability evidence within sample of engineering students. We utilized the EMARS scale with some minor modifications for measuring math anxiety in the context of learning calculus. The modified EMARS instrument is a five-point Likert scale which consists of (15) items. Item responses are ranged from strongly agree (5) to strongly disagree (1). The scale consists of four subscales: usefulness, persistency, fear of asking for help, and confidence. The three-item usefulness subscale assessed students' tendencies to see learning calculus as useful and worthwhile for their engineering, science, and information technology studies. Examples of usefulness items are "It is essential to understand the Calculus courses so that I can keep up with my science or information technology or engineering studies." and "I will need the knowledge gained in the calculus courses in the future". The three-item persistency subscale evaluated students to see learning mathematics as persistence and perseverance for their engineering, science, and information technology studies. Examples of persistency items are "I try not to skip the mathematics problems if they seem too difficult or too long for me" and "I do not get easily frustrated, if I don't right away find a solution to a mathematics problem."
\end{abstract}

The four-item fear of asking for help subscale assessed students to see learning calculus courses as avoid fear and anxiety of demanding for help for their engineering, science, and information technology studies. Examples of fear of asking for help items are "It is not difficult for me to ask for help when I don't understand a certain mathematics problem", "I do not feel anxiety, when asking for help in mathematics activities." and "If I need assistance in solving mathematical problems, I don't hesitate to ask for help from other students or course instructors.". Furthermore, the last subscale in the instrument is confidence with four-items that measure students' trends to realize learning mathematics courses to increasing self-confidence and assurance. Examples for confidence items are "Mathematics is my strong point", "I feel my mathematics skills are sufficient for science or information technology engineering studies.", and "Mathematical terminology is not strange for me, and I do not find it difficult to express mathematical phenomena with formulas."

The modified EMARS scale was translated into Arabic language and pilot tested on a sample of 55 students from the same population using 14 items. Then, the researchers omitted and reworded some of items that caused misunderstanding for some of students. 
Other reasons for rewording and/or omission were level of difficulty, discrimination being too low, and decrease in reliability. Based on specialists' advice, some items were added or omitted to make a total of 15 items.

According to items code, the negative statements ranged from 5 to 1 , and the positive statements were reversed. Then, the researchers developed the scale to measure 4 factors. These are: persistency which consists of 4 items with factor loading ranged between .363 to .742 ; usefulness of calculus which consists of 3 items with factor loading between .725 to .863 ; fear of asking for help which is made up of 4 items with factor loading between .685 to .777 ; and confidence which includes 4 items with factor loading between .503 to .764 .

The reliability coefficient for the overall scale is 0.792 , and the reliability coefficients for each subscale are as follows: persistency: 0.526; usefulness of calculus: 0.705; fear of asking for help: 0.706; and confidence: 0.563 .

\section{Study Design}

This study links some aspects of student background that is gender, faculty type (science, engineering, and information technology), length of studies (first, second, third, and fourth year), and postponement math courses, with mathematics anxiety, prior math performance, and GPA .It is best illustrated in diagrammatic form in Figure 1.The figure indicates the study hypothesizes that student background affect each the four aspects of math anxiety. Finally, the figure also hypothesizes that each of the aspects of math anxiety has an individual effect on GPA and calculus score 2.

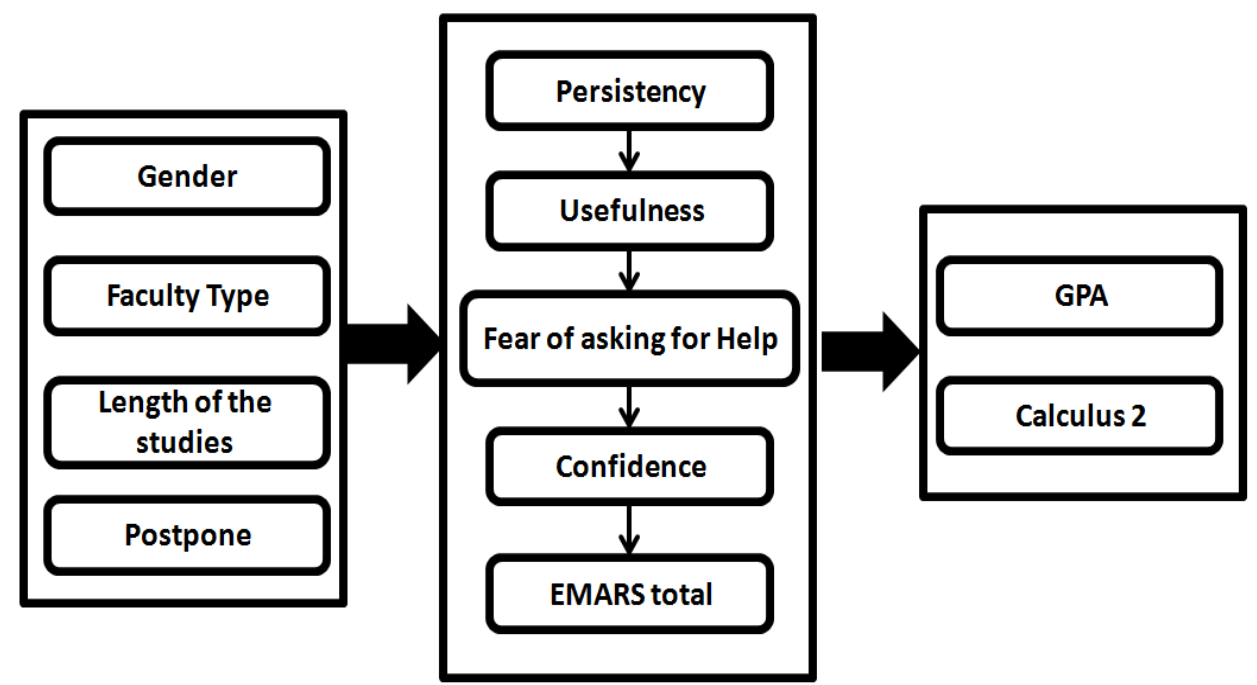

Figure 1

The Complete Model Showing Potential Links between the Background Variables Math Anxiety, GPA, and Calculus 2 


\section{Study Aims and Variables}

This study aims to investigate the relationship between math anxiety and mathematics performance. It is also aiming to examine any potential differences in math anxiety according to gender, faculty type, length of the studies, and postponement math courses.

\section{Study variables}

This study includes independent and dependent variables: Independent variables are: gender (Male or female), postponement math courses (yes, No), length of the studies (first, second, third, and fourth year), scientific facilities (science, engineering, and Prince Al-Hussein Abdallah II for information technology), and mathematics anxiety.

\section{Dependent variables}

Mathematics anxiety: the researchers considered math anxiety the overall student's anxiety instrument score

Prior math performance: the prior mathematics performance considered the student's Calculus 1 score.

Students' Performance (GPA): the researchers measured students' performance as grade point average (See Figure 1 above).

\section{FINDINGS}

What are the relationships between math anxiety subscales, students' performance (GPA), and prior math performance at AHU students?

As starting point, the relationship between mathematics anxiety subscales, students' performance, and prior math performance (Calculus 1 score), were examined using Pearson product -moment correlation coefficients. There was negative correlation between Calculus 1 score, and GPA with mathematics anxiety subscales and EMARS total. Whereas, there was positive correlation between GPA and calculus 1 score, and within subscales. The coefficients are shown in Table 1.

Table 1

Correlation Coefficients $\alpha$ for EMARS Subscales, EMARS Total, Math Prior, and GPA

\begin{tabular}{lllllll}
\hline & Confidence & Persistency & $\begin{array}{l}\text { Fear of Asking } \\
\text { for Help }\end{array}$ & Usefulness & $\begin{array}{l}\text { EMARS } \\
\text { Total }\end{array}$ & $\begin{array}{l}\text { Math } \\
\text { prior }\end{array}$ \\
\hline Confidence & 1 & & & & \\
\hline Persistency & $.589^{* *}$ & 1 & & & & \\
\hline $\begin{array}{l}\text { Fear of Asking } \\
\text { for Help }\end{array}$ & $.419^{* *}$ & $.398^{* *}$ & 1 & & \\
\hline Usefulness & $.381^{* *}$ & $.363^{* *}$ & $.243^{* *}$ & 1 & & \\
\hline EMARS Total & $.772^{* *}$ & $.772^{* *}$ & $.719^{* *}$ & $.697^{* *}$ & 1 & \\
\hline Math prior & $-.282^{* *}$ & $-.251^{* *}$ & $-.157^{*}$ & $-.410^{* *}$ & $-.397^{* *}$ & 1 \\
\hline GPA & $-.200^{* *}$ & $-.180^{*}$ & -.086 & $-.259^{* *}$ & $-.261^{* *}$ & $.597^{* *}$ \\
\hline$* \mathrm{p}<0.05 . * * \mathrm{p}<0.01$ & & & & & \\
\hline
\end{tabular}

Although all coefficients are statistically significant except GPA with fear of asking for help, there is a remarkable difference between the levels of the correlations within the 
four individual subscales, which range from 0.243 to 0.589 , with a mean of 0.399 . The level of correlation within the four subscales indicates a clear relationship, but also a clear indication that each of these scales is measuring something mainly independent of the other three scales. The correlations of the four scales with the total scores for EMARS ranged from .697 to .772 , with math prior and GPA ranged from -.086 to -.410, with a mean of- 0.288 .

The higher level of correlation between the four scales and the total for EMARS total is to be expected, given that the score for each scale is included in the total score. However, it was hypothesized that the different scales of math anxiety would be negatively related to math prior and GPA to varying extents. In summary, the correlations indicate that, when considered in isolation from each other, all four subscales were indirect correlation for math prior, and GPA with Usefulness with math prior the most negativity related and fear of asking for help with GPA the least related. The relationships with math prior and GPA of the four scales considered jointly will be taken up subsequently.

Do male and female differ in mathematics anxiety?

The independent samples t-test calculated to determine gender differences in EMARS subscales and in EMARS Total. The results showed that the mean score for EMARS subscales was not statistically significant in three subscales and in EMARS total. Only on fear of asking for help subscale males had more anxiety than females at $\alpha<.05$. Moreover, there were no gender differences in both GPA, and prior math performance. All Means, SD, T-value, and probability for EMARS subscales and EMARS total can be found in Table 2 .

Table 2

Means (and Standard Deviations), and Gender Means for EMARS Subscales

\begin{tabular}{lcccc}
\hline Gender & \multicolumn{5}{c}{ Female } \\
\hline Variable & $\mathrm{M}(\mathrm{SD})$ & $\mathrm{n}=100$ & $\mathrm{n}=79$ & $\mathrm{~T}(177)$ \\
\hline EMARS subscales & & & & \\
\hline Confidence & $2.98(0.75)$ & $3.01(0.71)$ & $2.95(0.79)$ & -0.560 \\
\hline Persistency & $2.24(0.68)$ & $2.31(0.67)$ & $2.14(0.69)$ & -1.700 \\
\hline Fear of Asking for Help & $2.33(0.81)$ & $2.45(0.80)$ & $2.19(0.80)$ & $-2.097^{*}$ \\
\hline Usefulness & $2.45(1.01)$ & $2.38(0.91)$ & $2.54(1.12)$ & 1.038 \\
\hline EMARS Total & $37.58(8.57)$ & $38.08(8.13)$ & $36.94(9.11)$ & 0.886 \\
\hline
\end{tabular}

Note. EMARS = Electromagnetics Mathematics Anxiety Rating Scale (5-point scale: $1=$ no anxiety; $5=$ very high anxiety)

a $15-75$ scale

$* \mathrm{p}<0.05$. $* \mathrm{p}<0.01, * * * \mathrm{p}<0.001$.

Are there any differences between faculty type and math anxiety?

The information technology students seem to stand out from the results. They show to have significantly more math anxiety compared to engineering and science students. Also, there was faculty type difference in prior math performance favoring engineering 
faculty. Whereas, there was no faculty type difference in relation to GPA. All Means, SD, F-value, and probability for EMARS subscales and EMARS total can be found in Table 3. According to the homogeneity, the homogeneity of the mathematics anxiety and faculty type through the Levene's test $(.929$, df1=2, df $2=176)$, the value of the Levene's test is .397 , which is not statistically significant. This means that there is homogeneity in the data of the math anxiety variable and faculty type.

Table 3

Means (and Standard Deviations), and Faculty Group Means for EMARS subscales.

\begin{tabular}{lccccc}
\hline \multicolumn{7}{c}{ Faculty } \\
\hline Variable & \multicolumn{2}{c}{ Engineering } & Science & Information Technology \\
\hline \multicolumn{7}{l}{ M (SD) } & $\mathrm{n}=6$ & $\mathrm{n}=79$ & $\mathrm{n}=38$ & $\mathrm{~F}(2,176)$ \\
\hline Confidence & $2.98(0.75)$ & $2.87(0.71)$ & $2.91(0.71)$ & $3.32(0.75)$ & $5.62^{* *}$ \\
\hline Persistency & $2.24(0.68)$ & $2.24(0.61)$ & $2.04(0.65)$ & $2.63(0.70)$ & $10.71^{* *}$ \\
\hline Fear of Asking for Help 2.33(0.81) & $2.35(0.79)$ & $2.14(0.80)$ & $2.70(0.74)$ & $6.49^{* * *}$ \\
\hline Usefulness & $2.45(1.01)$ & $2.22(0.87)$ & $2.30(1.01)$ & $3.18(0.89)$ & $14.38^{* * *}$ \\
\hline EMARS Total & $37.58(8.57)$ & $36.53(7.89)$ & $35.27(7.89)$ & $44.11(7.89)$ & $16.94^{* * *}$ \\
\hline
\end{tabular}

Are there any differences between length of the studies and math anxiety?

One way ANOVA was conducted to examine length of the studies (academic year) with math anxiety subscales and EMARS Total; the results showed that were significant differences between length of the studies with all math anxiety scales and EMARS Total at $(\alpha<.01)$. For the EMARS Total, F-value was 11.78 , and length of the studies means $31.56,36.57,41.72$, and 44.41 respectively from first to fourth year. In addition, there were length of the studies differences in both GPA and prior mathematics performance favoring first year. The overall means, length of the studies range, SD, F-value, and probability can be found in Table in Table 4. According to the homogeneity test, the homogeneity of the mathematics anxiety and the length of the studies through the Levene's test $(.592, \mathrm{df} 1=3$, df2=175), the value of the Levene's test is 0.62 , which is not statistically significant. This means that there is homogeneity in the data of the math anxiety variable and faculty type.

Table 4

Overall Means, Length of the Studies Range, SD, F-Value, and Probability

\begin{tabular}{lllll}
\hline Scale & Overall mean $(\mathrm{SD})$ & Length of the studies & F-value & $\mathrm{A}$ \\
\hline Confidence & $2.98(0.75)$ & $2.38-3.36$ & 11.78 & .000 \\
\hline Persistency & $2.24(0.68)$ & $1.92-2.38$ & 9.93 & .000 \\
\hline $\begin{array}{l}\text { Fear of asking for } \\
\text { help }\end{array}$ & $2.33(0.81)$ & $2.09-2.70$ & 4.34 & .006 \\
\hline Usefulness & $2.45(1.01)$ & $1.96-2.76$ & 11.77 & .000 \\
\hline EMARS Total & $37.58(8.57)$ & $31.56-44.41$ & 16.94 & .000 \\
\hline
\end{tabular}

Are there any differences between students who postpone math course in mathematics anxiety and from those students who take core math courses from the first year?

The postpone mathematics courses (calculus 1 and calculus 2) mean scores on each of the four subscales of math anxiety and the EMARS total scores were compared using t- 
tests. There was a significant postponing difference for all four subscales and EMARS total scores at $\alpha<.0 .001$ The students who postpone math courses had significantly higher anxiety scores than other students and for EMARS total as well. Moreover, there were postponing differences in both GPA, and prior math performance favoring those who did not postpone math courses. The mean scores and SD by postpone are shown in Table 5 .

Table 5

Means (and Standard Deviations), and Postpone (Yes, No) Means for EMARS Subscales

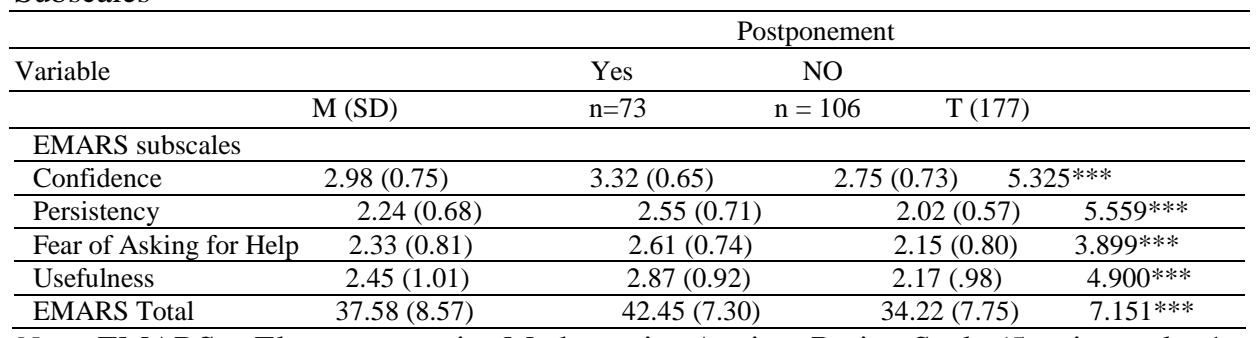

Note. EMARS = Electromagnetics Mathematics Anxiety Rating Scale (5-point scale: $1=$ no anxiety;

$5=$ very high anxiety)

a $15-75$ scale

$* \mathrm{p}<0.05$. $*$ p $<<0.01, * * * \mathrm{p}<0.001$

\section{DISCUSSION AND CONCLUSION}

The core finding of this study was that all four math anxiety subscales and EMARS total had a negative correlation with math performance. This result was expected and consistent with other previous studies (Ashcraft \& Kirk, 2001; Daley, 1999; Ma, 1999; $\mathrm{Ma} \& \mathrm{Xu}, 2004)$. The result agrees also with the study by (Hembree 1990; Hodge 2002) who reported that high math anxiety associates with poor math performance and low math self-efficacy. This result is due to math anxiety bothering and negatively effecting on mathematics performance, and math anxiety as presence the cause of errors in ability of students in doing mathematical tasks (Bull, 2009). Nevertheless, the students in this study revealed a level of math anxiety that was related to math courses (i.e. calculus $1 \&$ 2) and GPA.

The negative relation between anxiety and performance in mathematics reported in this study indicate that math anxiety has knowledge and emotional sides. Helping students to overcome the cognitive difficulties in learning mathematics, can have a role in reducing math anxiety, which is supported by (Hunsley, 1987) study that conformed cognitive aspect of learning mathematics associated with math anxiety.

In relation to gender differences in math anxiety, the results revealed that there were no significant differences found. Although this result was inconsistent with (Ma, 1999, Wahid, Yusof,\& Nor, 2018)., it is consistence with other studies (Dane, 2005; Peker \& Ertekin, 2011). The mean scores for gender are not reflected to be a variable that is 
connected to mathematics anxiety. Furthermore, the faculty type, such as Information Technology students, show to have significantly higher math anxiety scores compared to engineering and science students. In addition, there was difference in prior math performance favoring engineering faculty. This result attributed to the information technology students to have high math anxiety due to mathematics learning difficulties, which show on their low scores on calculus and GPA.

In regards to length of the studies, the results noted that there were differences in this variable with math anxiety, fourth year students had high math anxiety scores and the first-year students had the lowest. This result is expected, since the students who took math courses in their year of graduation more likely to experience more math anxiety. Finally, according to the postponed mathematics courses, the result showed that there was a significant postponing difference for all four subscales and EMARS total scores. The students who postpone math courses had significantly higher anxiety scores than other students and for EMARS total as well. This result was expected due to most of students who have math anxiety more likely to postpone math courses until the last years, particularly Calculus 2. Moreover, postponed mathematics courses were related to the length of the studies, the students who took postponed math course took these courses in the third or fourth years, specifically Information Technology students and vice versa.

Mathematics is considered as an important subject for all educational levels including university level. According to the poor mathematics performance, there is interaction for many factors to cause math anxiety, which is interfering in mathematics performance. Therefore, it is important to decrease math anxiety. Decreasing the anxiety is expected to increase mathematics achievement through encouraging students to ask for help, increase their confidence in dealing with mathematical problems, and improving students' persistency.

\section{REFERENCES}

Artemenko, C., Daroczy, G., \& Nuerk, H.C. (2015). Neural correlates of math anxietyan overview and implications. Frontiers in Psychology, 6, 1-8. doi: 10.3389/ fpsyg.2015.01333.

Ashcraft, M., \& Kirk, E. (2001). The relationship among working memory, math anxiety, and performance. Journal of Experimental Psychology. General, 130(2), 224-237.

Ashcraft, M., \& Moore, A. (2009). Mathematics anxiety and the affective drop in performance. Journal of Psychoeducational Assessment, 27(3), 197-205.

Bessant, K. C. (1995). Factors associated with types of mathematics anxiety in college students. Journal for Research in Mathematics Education, 26, 327-345. doi: $10.2307 / 749478$.

Brunyé, T. T., Mahoney, C. R., Giles, G. E., Rapp, D. N., Taylor, H. A., \& Kanarek, R. B. (2013). Learning to relax: Evaluating four brief interventions for overcoming the negative emotions accompanying math anxiety. Learning and Individual Differences, 27, 1-7. doi: 10.1016/j. lindif.2013.06.008. 
Bull, H. (2009). Identifying maths anxiety in student nurses and focusing remedial work. Journal of Further and Higher Education, 33(1), 71-81.

Burns, M. (1998). Math: facing an American phobia. Sausalito, CA: Math Solutions Publications.

Crawford, K., Gordon, S., Nicholas, J., \& Prosser, M. (1994). Conceptions of mathematics and how it is learned: The perspectives of students entering university. Learning and Instruction, 4(4), 331-345.

Dane, A. (2005). Differences in mathematics anxiety by sex, program, and education of University mathematics students in Turkey. Psychological Reports, 96(2), 422 -424.

Gilham, D., \& Chu, S. (1995). An analysis of student nurses' medication calculation errors. Contemporary Nurse, 4(2), 61-64.

Guita, G., \& Tan, D. (2018). Mathematics anxiety and students' academic achievement in a reciprocal learning environment. International Journal of English and Education, $7(3), 112-124$

Greenwood, J. (1984). My anxieties about math anxiety. Mathematics Teacher, 77(9),662-663.

Hembree, R. (1990). The nature, effects, and relief of mathematics anxiety. Journal for Research in Mathematics Education, 21(1), 33-46.

Hodge, J. (2002). The effect of math anxiety, math self-efficacy, and computer-assisted instruction on the ability of undergraduate nursing students to calculate drug dosages (Unpublished doctoral dissertation). West Virginia University Morgantown, WV, US.

Hourigan, M., \& O’Donoghue, J. (2007). Mathematical under-preparedness: the influence of the pre-tertiary mathematics experience on students' ability to make a successful transition to tertiary level mathematics courses in Ireland. International Journal of Mathematics Education in Science and Technology, 38(4), 461-476.

Hunsley, J. (1987). Cognitive processes in mathematics anxiety and test anxiety: The role of appraisals, internal dialogue, and attributions. Journal of Educational psychology, 79(4), 388-392.

Luk, H. S. (2005). The gap between secondary school and university mathematics. International Journal of Mathematics Education in Science and Technology, 36(2/3), 161-174.

Leppävirta, J. (2011). The impact of mathematics anxiety on the performance of students of electromagnetics. Journal of Engineering Education, 100(3), 424-443.

Leppävirta, J. (2007). Developing an instrument to measure engineering students' mathematics anxiety when learning electromagnetics. Proceedings in ReflekTori2007, Symposium of Engineering Education, Espoo, Finland. 
Ma, X. (1999). A meta-analysis of the relationship between anxiety toward mathematics and achievement in mathematics. Journal for Research in Mathematics Education, 30, 520-540.

Ma, X., \& Xu, J. (2004). The causal ordering of mathematics anxiety and mathematics achievement: a longitudinal panel analysis. Journal of Adolescence, 27, 165-179.

Metje, N., Frank, H., \& Croft, P. (2007). Can't do maths -understanding students' maths anxiety. Teaching Mathematics and its applications, 26(2), 79-88.

Norwood, K. S. (1994). The effects of instructional approach on mathematics anxiety and achievement. School Science and Mathematics, 94(5), 248-254.

Onwuegbuzie, A. J., \& Daley, C. (1999). Perfectionism and statistics anxiety. Personality and Individual Differences, 26(6), 1089-1102.

Peker, M., \& Ertekin, E. (2010). The relationship between mathematics teaching anxiety and mathematics anxiety. New Educational Review, 23(1), 213-226.

Richardson, F., \& Suinn, R. (1972). The mathematics anxiety rating scale: psychometric data. Journal of Counselling Psychology, 19, 551-554.

Stuart, V. (2000). Math curse or math anxiety? Teaching Children Mathematics, 6(5), 330-335.

Tariq, V. N., \& Durrani, N. (2011). Factors influencing undergraduates' self-evaluation of numerical competence. International Journal of Mathematical Education in Science and Technology, 1-20. doi: 10.1080.0020739X2011.618552.

Tobias, S. (1994). Overcoming math anxiety. NY: W.W. Norton.

Wahid,S., Yusof, Y., \& Nor, A. (2018). Effect of mathematics anxiety on students' performance in higher education level: A comparative study on gender. AIP Conference Proceedings 1974, 050010. doi: 10.1063/1.5041710.

Woodard, T. (2004). The effects of math anxiety on post-secondary developmental students as related to achievement, gender, and age. Inquiry, 9(1), 1-5. 